\title{
Sustainable Urban Mobility: Challenges, Initiatives and Planning
}

\author{
Viswanadha Kumar Giduthuri \\ Department of Architecture, Andhra University, Visakhapatnam, India \\ Email: giduturi.viswanadh@gmail.com
}

Received 24 June 2015; accepted 12 September 2015; published 15 September 2015

Copyright (C) 2015 by author and Scientific Research Publishing Inc.

This work is licensed under the Creative Commons Attribution International License (CC BY). http://creativecommons.org/licenses/by/4.0/

(c) () Open Access

\section{Abstract}

The growth of cities is not spontaneous and uncontrollable but guided and shaped by human interaction and by physical infrastructure. However, urban expansion around the world is characterised by uncontrolled urban sprawl leading to inefficient use of space and natural resources. Interactions between humans and opportunities for innovations are constrained by low density and social segregation. For the cities and towns to function efficiently, accessibility is essential to carry the goods and for services. But accessible cities are being encouraged to shift towards more sustainable modes of transportation and draw more travelers in different modes of transport including sidewalks. Mobility is about more than just the mode of transport available. Urban planning and design should focus on how to bring people and places together, by creating cities that focus on accessibility and optimal urban densities, rather than simply increasing the length of urban transport infrastructure. This paper gives a brief review of urban planning initiatives taken by government of Indian towards a sustainable urban mobility plans and outlines urban planning challenges for the local urban bodies, urban designers and policy makers.

\section{Keywords}

Urban Mobility, Urbanization, Non-Motorization, Health and Environment

\section{The Challenges}

The growth of cities is not spontaneous and uncontrollable but guided and shaped by human interaction and by physical infrastructure. However, urban expansion around the world is characterised by uncontrolled urban sprawl leading to inefficient use of space and natural resources. Interactions between humans and opportunities for innovations are constrained by low density and social segregation. At this juncture, urban planning has a critical role to play in improving people's wellbeing and the quality of life. International conferences on sus- 
tainable development have highlighted this message right from the United Nations Conference on Environment and Development in Rio de Janeiro in 1992 to the United Nations Conference on Human Settlements (Habitat II, the City Summit) in Istanbul in 1996 (Musoga, 2011). Spatial planning is a key instrument for working towards sustainable development at the local level. More specifically, urban planning is a potent tool both for reducing the overall impact of settlements on the regional environment and for improving conditions within settlements (loc.cit).

As per latest statistics, over 50 percent of the world's population lives in cities and around the world, more than 1 million people migrate every week from rural areas to cities, imposing huge burdens on the existing infrastructure, especially transport systems. This alarming pace of urbanization has been leading to enormous personal motorization that drastically aggravates carbon emissions polluting the environment, which in turn cause innumerable health problems to humans and even to other life forms. These developments continue and contribute to catastrophic climate change if cities do not develop more sustainable transportation options (Tsay \& Herrmann, 2013). Thus the uncontrollable growth of cities poses a challenge to city planners and those dealing with transportation. To respond to the said problem in fast growing cities, investments in sustainable options are essential to achieve socially inclusive, economically efficient and environmentally friendly measures.

\section{The Initiatives}

In efforts to promote sustainable urban development worldwide, the United Nations agency for human settlements, UN-HABITAT advocates better conditions for non-motorized transport options to reduce greenhouse gas emissions. Non-motorized transport is defined as any form of transportation that provides personal or goods mobility by methods other than fuel powered engines including electric power. This would include walking, trips by bicycles and tricycles, human porterage, handcarts and wheelbarrows; animal drawn carts and other human powered vehicles.

World Habitat Day is also intended to highlight the state of our towns and cities and the basic right of adequate shelter to all. It also aims to remind the world to shape the future cities and towns for sustainable urban mobility as the topmost need. Multiple actors, including national and local governments, must work together to create environmentally and financially sustainable urban transport systems (Tsay \& Herrmann, 2013). In this context, it is apt to recall the Global Report on Human Settlement 2013 which elaborately deals with various aspects of urban transport issues. The report points out that providing transport is not merely the issue, but it requires a conceptual leap to assess various modes of transport for reaching the work places and accessing social services like hospitals and entertainment avenues such as theatres, quickly with ease without causing much pollution (Pardo, 2010). For this, integrated land use and transport planning are very crucial (Pardo et al., 2010; Sukumaran, 2013).

Today, mobility and accessibility are the two key components in designing and expanding of cities for efficient functioning of different systems as well as delivering of various goods and services. Mobility is the mode of transport and accessibility is the urban infrastructure that needs to support mobility plans. But mobility is about more than just the mode of transport involved. Accessible cities shall encourage a shift towards more sustainable modes of transportation including pedestrian ways. Thus, urban planning and design should focus on to bring people and places together by creating focus on accessibility and optimization of urban densities rather than simply increasing the length of urban transport infrastructure.

\section{Urban Transformation in India}

According to India Census (2011), urban population in the country is 377 million. On an international scale, India has witnessed fastest urbanization rates during last decade or two in the developing world. India's urban population increased from 17.3 percent in 1971 to 23.3 percent in 1981, 27.78 percent in 2001 and expected to increase 38\% in 2026 (GoI, 2011a). The 2011 Census figures reveal that over 31 per cent of the country's population is presently living in urban areas. This of course is lower than that for China, Indonesia, Mexico or Brazil (GoI, 2011b). Lohia (2011) pointed out that motorization rates are high in 6 Metro Cities between 1981 and 2001 and this growth rate equaled ratio of population vs. motor vehicles is $2: 8$, which is really a stumbling block in attaining sustainable urban mobility.

Of course, public transport is increasingly coming into focus as more buses have been purchased and put on road under the Urban Renewal Mission. However, the lack of comprehensive planning of transport systems, 
without any consideration to social, economic, environmental and cultural elements of the city is likely to result in physical breaks in the fabric of communities and reinforce social exclusion. Further, the impact on quality of life and the environment cannot be under estimated. Thus a clear vision is lacking among planners and administrators in tackling the problems (Pardo et al., 2010; Sukumaran, 2013). While discussing on sustainability of transportation in Indian cities, Newman (2013) explained about the current practices in Australia and suggested that each city in India should also provide space for pedestrians, bikes and public transport in that order of priority.

\section{Initiatives of the Government of India}

As many as 63 cities across India, demonstrating vision and creativity have introduced innovative measures in urban planning, management and governance following central government policy innovations such as Jawaharlal Nehru National Urban Renewal Mission (JNNURM) of 2005. These innovations have triggered some changes, but sidestepped the existing planning processes that seem too complicated to be amenable for any change (GoI, 2005). This reform based mission is meant for extending Central Financial Assistance (CFA) to Urban Local Bodies and includes betterment of urban transport planning and management through 1) Comprehensive Mobility Plan (CMP), 2) Unified Mass Transit Authority (UMTA), 3) Dedicated Urban Transport Fund at state and city level, 4) Transit Oriented Development Policy, Parking Policy and Advertisement Policy, 5) city specific Special Purpose Vehicle for managing public transport, 6) Traffic Information and Management Control Centre, etc., 7) Use of ITS and integration of multi-modal systems, 8) Bus prioritisation at intersections, dedicated/demarcated lanes for buses, 9) Designate a nodal department for urban transport and 10) Mechanism for periodic revision of public transport fares (Lohia, 2011). Integration of transport and land use planning is a key suggestion of the National Urban Transport Policy adopted in 2006, and Transit-oriented Development is gradually becoming a strategic point of focus in several key cities such as Delhi.

In fact, urban transport is witnessing quite some innovation but mobility is a serious challenge in most Indian cities and towns mainly due to inadequate transport infrastructure, unbalanced modal split heavily favouring private transport and little integration between land use and transport planning. Private transport is increasing by leaps and bounds every day but roadways remain the same or at best increase marginally (Suri, 2011).

Improvement in public transport is becoming increasingly common characterized by innovative planning combined with the use of modern technology in major metropolitan cities of India. For instance, all modes of public transport, including Bus Rapid Transit system (BRTS) and metro rail are resorting the use of Compressed Natural Gas (CNG). Public service vehicles in the National Capital Territory run on CNG for over a decade now. This policy introduced in 2001-02 under the directives of the Supreme Court of India; is implemented now effectively and as a result the capital became relatively free of diesel smoke. For example, between 2000 and 2008 carbon emissions in the metropolis had plummeted by $72 \%$ while $\mathrm{SO}_{2}$ emissions decreased by $57 \%$, though 3500 buses, 12,000 taxis, 65,000 auto rickshaws and 5000 mini buses are plying in and around the mega city solely due to the use of CNG (Hohne \& Burck., 2009). Buses serve as the most important mode of public transport across all cities. Bus Rapid Transit System Projects for 437 km (Pune-101.77 km, Pimpri Chinchwad-42.22 km, Indore-11.45 km, Bhopal-21.71 km, Ahmedabad-88.50 km, Jaipur-39.45 km, Vijayawada- $15.50 \mathrm{~km}$, Visakhapatnam-42.80 km, Rajkot-29.00 km, Surat-29.90 km and Kolkata-15.00 km) were sanctioned to 10 mission cities in the country at a total cost of US \$1085 million (@US \$ 2.4 million per km). Urban Ministry is supporting Metro Rail projects to serve high demand corridors in bigger cities such as Delhi $(117.00 \mathrm{~km})$, Mumbai (62.89 km), Bangalore (42.30 km), Kolkata (14.67 km), Chennai (46.50 km), Hyderabad (71.00 km) and Kochi $(25.30 \mathrm{~km})(\mathrm{GoI}, 2011 \mathrm{a})$.

\section{The Planning}

Master planning has been a fundamental tool of urban development and management for long, but in recent years it has been found to be less effective. The shortcomings are mainly due to usual exclusion of community groups, target beneficiaries and nongovernmental organizations from the processes of planning, promotion and participation.

The functioning of a city is linked to its means of physical communication, i.e., its transportation infrastructure. Transportation infrastructure shapes urban development very strongly facilitating activities and land densification along the existing corridors and networks. Therefore, the management of urban growth needs to rely on 
an approach that integrates urban development and spatial organization of the city along with transportation network (rail-road) (Toutain \& Gopiprasad, 2006).

Pardo (2010) had suggested four measures for sustainable urban transport, namely, 1) public transport, 2) subway and light-rail system, 3) metro and urban light-rail system and 4) non-motorized transport.

Public transport: This measure implies the development of high quality public transport systems including mass transit systems. A specific public transport mode called Bus Rapid Transit (BRT) has been generally favoured in recent years due to its moderate cost, relatively short implementation time and high quality of service with capacity to move large number of passengers.

Subway and light-rail systems: This is a means of rapid, cost-effective and environmentally benign urban passenger transport. For example, 116 cities located mostly in industrialized countries operate their own metro systems, which are used by an estimated 155 million passengers each day. In addition, there are about 400 rail systems worldwide while over 200 new systems are being planned. Many megacities in developing countries are also investing in the construction, modernization and expansion of urban light-rail systems.

Metro and urban light-rail systems: This system is costly to construct and maintain but can provide significant long-term economic, social and environmental benefits. Various studies analyzing investment in urban public transport infrastructure and services have shown that in the long term the sum of public benefits by far exceed the investment costs. Urban public transport systems are more attractive for commuters and more economically viable for operators if they offer the option to travel from any point in the city to any other point. This can be achieved through the expansion of network as well as through intermodal connections.

Non-motorized transport: Also called "Active Transport", it essentially refers to walking and cycling (and all other modes that have wheels but no engine such as pedicabs and freight tricycles), as well as related infrastructure, policies and education.

All these transport modes have been greatly promoted in recent years due to lot of short and long term benefits in reducing greenhouse gas emissions and for ensuring healthy environment.

Urban planning practices shall be geared up to reflect a new awareness and to integrate environmental, health, economic and social concerns of the $21^{\text {st }}$ century (UN-Habitat, 2013). The key challenges in many cities of developing countries and emerging economies are lack of awareness about the wide benefits of non-motorized infrastructure and scarce financial resources for the implementation of necessary projects (Anonymous, 2011). Sustainable urban mobility practices from various internationally acknowledged case studies mention that auto-free zones, bikeway, bike-sharing, bus rapid transit, carpooling, car-sharing, congestion charge, demand-responsive public transport, flyover/overpass, integrated planning and pedestrian ways play an important role in integrated environmental, health, economic and social concerns during the preparation of mobility plans for a city or a town.

\section{Conclusion}

Cities need to be more consciously planned to address sustainable urban transport appropriately. A strategic plan for urban mobility is required to achieve better quality of life that builds on existing planning practices with due consideration to urban mobility. However, for the process to be successful there is a need for proper policy framework, adequate manpower with requisite planning skills and facilities, sufficient financial resources and a well structured citizen participation framework. In addition, adequate time should be allocated for proper stakeholder engagement.

The challenges and responsibilities of preparation and implementation of sustainable mobility plans shall be taken up by different planning professionals, viz., auto-free zones and integrated planning by the local urban planning authorities, designing of bikeway, cycle tracks, bus rapid transit, light rail, demand-responsive public transport, flyover/overpass and pedestrian ways by urban designers and policy making on bike-sharing, carpooling, car-sharing, congestion charge by policy makers for the existing cities and for their future expansion while, widely publicising them for the benefit of the public at large.

The cities planned with transport modes as an integrated system are more likely to evolve and prosper as centers of trade, commerce, industry, education, tourism and services. Generally, cities ranking at the top of surveys measuring urban quality of life have high quality urban transport systems that prioritize public transport and non-motorized modes. 


\section{Acknowledgements}

The author acknowledges sincere thanks to Mr. M. V. Rao, Scientist, Wood Biodegradation centre (Marine), Institute of Wood Science and Technology, Visakhapatnam for valuable critiques and advice in the preparation of manuscript.

\section{References}

Anonymous (2011). Planning and Investing for Sustainable Urban Mobility in Developing Countries and Emerging Economies-The Role of the Bicycle. Conference "Velocity Question Workshop" at Santa Clara, San Francisco, 23 September 2011.

GoI (2005). Jawaharlal Nehru National Urban Renewal Mission (JNNURM): Overview. New Delhi: Ministry of Urban Development, Ministry of Housing and Urban Poverty Alleviation.

GoI (2011a). Urban Transport Initiatives in India: Best Practices in PPP (121 p). New Delhi: National Institute of Urban Affairs, Government of India.

GoI (2011b). Report on Indian Urban Infrastructure and Services. The High Powered Expert Committee (HPEC) for Estimating the Investment Requirements for Urban Infrastructure Services (284 p). New Delhi: National Institute of Urban Affairs, Government of India.

Hohne, N., \& Burck, J. (2009). Scorecards on Best and Worst Policies for Green New Deal, WWF and E3G.

India Census (2011). censusindia.gov.in/2011-prov-results/paper2/data files/india/Rural_Urban_2011.pdf

Lohia. S. K. (2011). Sustainable Urban Transport; Initiatives by Govt. of India. Third Biennial IHCN Conference: Urban Mobility in Heritage Cities, Mysore, 14-17 May 2011.

Musoga, G. K. (2011). Strategic Urban Development Planning in Lake Victoria Region: Lessons of Experience (66 p). United Nations Human Settlements Programme (UN-HABITAT).

Newman, P. (2013). The Future Lies in Rail. “The Hindu” Habitat, 13 October 2013, 4.

Pardo, C. F., Jiemian, Y., Yu, H. Y., \& Mohanty, C. R. (2010). Chapter 4, Sustainable Urban Transport, Shanghai Manual-A Guide for Sustainable Urban Development in the 21st Century (38 p).

http://www.un.org/esa/dsd/susdevtopics/sdt pdfs/shanghaimanual/shanghaimanual.pdf

Sukumaran, K. (2013). Cities Need a Conceptual Lead. “The Hindu” Habitat, 13 October 2013, 4.

Suri, S. N. (2011). Making Indian Cities Liveable: The Challenges of India's Urban Transformation. Proceedings of the Conference on Liveable Cities: Urbanizing World. An Introduction to the Review, ISOCARP, Wuhan, 20-41.

Toutain, O., \& Gopiprasad, S. (2006). Planning for Urban Infrastructure. India Infrastructure Report, 59-81.

Tsay, S., \& Herrmann, V. (2013). Rethinking Urban Mobility: Sustainable Policies for the Century of the City (68 p). Washington, DC: Carnegie Endowment for International Peace.

UN-Habitat (2013). Draft Quick Guide 2: Developing an Urban Mobility Plan. UNHABITAT | EMBARQ: 58. 